\title{
Association Between Air Temperature and the Incidence of Acute Coronary Heart Disease in Northeast China
}

This article was published in the following Dove Press journal:

Clinical Interventions in Aging

\section{Xue Wang $\mathbb{D}^{\prime}$ \\ Yizeng Jiang ${ }^{2}$ \\ Yingzhe $\mathrm{Bai}^{3}$ \\ Chao Pan $^{2}$ \\ Renzi Wang ${ }^{4}$ \\ Miao $\mathrm{He}^{\prime}$ \\ Jinghai Zhu'}

'Institute of Environmental and Health, School of Public Health China Medical University, Shenyang, People's Republic of China; ${ }^{2}$ Department of Emergency, Horqin District First People's Hospital of Tongliao, Tongliao, People's Republic of China; ${ }^{3}$ Department of Air Detection Information Technology Support Center, Tongliao Meteorological Observation, Tongliao, People's Republic of China; ${ }^{4}$ Department of Clinical Medicine, Air Force Medical University, Xian, People's Republic of China
Correspondence: Jinghai Zhu

Institute of Environmental and Health, School of Public Health China Medical University, Puhe Road 77, Shenyang, Shenbei I I0122, People's Republic of China Email zhujinghai2019@163.com
Aim: The aim of this study was to examine the association between air temperature and incidence of acute coronary heart disease in Northeast China.

Methods: We obtained coronary heart disease (CHD) daily hospitalization data from January 2017 to June 2019, and collected meteorological data including average daily air temperature, air pressure, relative humidity, wind velocity, sunshine duration and water vapor pressure, for the same period. Totally, This study included data from 6775 patients with CHD.

Results: After adjusting for confounding factors, low air temperature was inversely associated with CHD. Additionally, in the warm season (April-September), the number of daily hospital admissions for CHD was higher $\left(\geq 24.2^{\circ} \mathrm{C}\right)$ if the average daily air temperature was low $\left(\leq 15.4^{\circ} \mathrm{C}\right)$.

Conclusion: Low air temperature might be a risk factor for CHD among the elderly, especially in the warm season.

Keywords: air temperature, coronary heart disease, elderly, warm season, cold season

\section{Introduction}

Since the 1950 s, coronary heart disease (CHD) has become a major noncommunicable disease with a tremendous public health burden. CHD is divided into five types: asymptomatic myocardial ischemia, angina pectoris, myocardial infarction, ischemic heart failure and sudden death. The World Health Organization has reported that 740 million people died of CHD in 2012. ${ }^{1}$ According to the 2018 China Cardiovascular Disease Report, there were 290 million cardiovascular patients in China, 11 million of whom had CHD. ${ }^{2}$ CHD is especially detrimental to the middle-aged and the elderly populations, ${ }^{3}$ and with an increasing aging population, China will be confronted with a serious problem in that more elderly people may suffer from CHD. Therefore, it is important to identify the risk factors for CHD among the elderly.

Meteorologically, China is characterized by a temperate monsoon climate, and compared to other countries in the same latitude, winter in China is the coldest. The area selected for this study is located in Northeast China and has a typical temperate continental monsoon climate that is characterized by a large annual temperature difference, concentrated precipitation, four distinct seasons and low annual rainfall. Some studies have shown that meteorological factors have an impact on $\mathrm{CHD}^{4,5}$ with air temperature playing an important role as both low and high air 
temperatures may cause an increase in CHD mortality. ${ }^{6-9}$ To date, most studies have focused on the relationship between air temperature and CHD mortality, while few studies have addressed the relationship between air temperature and CHD morbidity. Further, previous studies had not adjusted their analyses for the confounding effects of other meteorological factors, and most studies focused on extreme events, with few studies assessing the effects of moderately high or low temperatures. Therefore, this study aims to investigate the relationship between air temperature and acute CHD morbidity after adjusting for meteorological variables such as air pressure, wind velocity, relative humidity, sunshine duration, and water vapor pressure in temperate continental monsoon climate, especially during winter, in Tongliao, Northeast China.

\section{Materials and Methods Health Data}

Data on daily hospital admissions for CHD were collected from the electronic records of the Horqin District First People's Hospital of Tongliao, from January 2017 to June 2019. Data retrieved included admission date, diagnostic code of each admission, and age and gender of the patients. All patients included in this study were diagnosed with CHD according to the International Classification of Diseases, Revision 10 (ICD-10), which includes acute myocardial infarction (I21-I22), unstable angina (I20.0), stable ischemic heart disease (I20 except I20.0, I25), and other types of CHD (including recent complications after acute myocardial infarction and other acute ischemic heart disease, I23-I24). This study included daily hospital admission records of 6775 patients with CHD and was approved by the ethical standards of the Committee on Human Experimentation of the China Medical University. The patients agreed to review the case report for scientific research, and this study follows the principle of confidentiality and the Helsinki declaration. The study keeps patient data strictly confidential.

\section{Meteorological Data}

We collected historic climate data for the period between January 2017 and June 2019 from the Tongliao Meteorological Administration. Average daily values for air temperature, air pressure, relative humidity, wind velocity, sunshine duration and water vapor pressure were collected by weather stations across Tongliao, and used in this study. Any weather stations that did not record any of the above meteorological variables were not considered for inclusion in the analysis.

\section{Statistical Analysis}

ANOVA or Chi-square test was used to evaluate the correlation between the number of CHD daily hospitalizations and sample characteristics such as age, gender, season classification. Simultaneously, we divided the study population into two groups based on median age as group 1 ( $\leq 66$ years) and group 2 ( $>67$ years). The number of CHD daily hospitalizations and the average daily air temperature were classified into quartiles as follows: (a) $\min (\leq 4), 25 \%(5-7), 75 \%$ (8-10), and $\max (\geq 11)$; (b) $\min (\leq-5), 25 \%$ (-4.8-9.2), $75 \%$ (9.3-20.1), and $\max (\geq 20.2)$. The cold season (lasts from October to March), which the warm season (runs from April to September). Ordinal logistic regression was used to explore the relationship between average daily air temperature and the number of CHD daily hospitalization quartiles. Statistical analyses were conducted using SPSS ver. 20.0 software (IBM). A P-value of less than 0.05 was regarded as statistically significant.

\section{Result Description of the Study Population}

As shown in Table 1, data on daily hospitalizations were recorded, retrieved for 6775 CHD patients; their mean age was $65.76 \pm 11.18$ years and $52.2 \%$ were male.

\section{Description of the Meteorology}

The distribution of weather factors in Tongliao from January 2017 to June 2019 is summarized in Table 2. Tongliao's climate is typically temperate with continental monsoon characterized by hot, rainy summers, and cold, dry winters.

\section{Relationship Between Air Temperature and CHD}

Table 3 shows that after controlling for confounding factors such as air pressure, wind velocity, relative humidity, sunshine duration and water vapor pressure, low air temperature may be a risk factor for CHD. Additionally, lower air temperature was associated with CHD daily hospitalization quartiles, irrespective of the age group $(\mathrm{OR}=5.61,95 \% \mathrm{CI}$ : 2.35-13.40; OR=2.43, 95\% CI: 1.02-5.77). Table 4 shows that the relationship between air temperature and CHD daily hospitalization quartiles was more significant in the warm season than in the cold season, irrespective of whether 
Table I The Characteristics of CHD Patients by Levels of Daily CHD Hospitalizations

\begin{tabular}{|c|c|c|c|c|c|c|}
\hline & \multicolumn{5}{|c|}{ CHD Daily Hospitalization Quartile } & \\
\hline & $I(655)$ & $2(1383)$ & $3(1884)$ & $4(2853)$ & Total(6775) & \\
\hline \multicolumn{7}{|l|}{ Mean \pm SD } \\
\hline Age & $67.13 \pm 11.34$ & $66.39 \pm 11.42$ & $65.59 \pm 10.92$ & $65.26 \pm 11.15$ & $65.76 \pm 11.18$ & $<0.001$ \\
\hline \multicolumn{7}{|l|}{ N (\%) } \\
\hline Female & $342(52.20 \%)$ & $695(50.30 \%)$ & $988(52.40 \%)$ & $151 \mid(53.00 \%)$ & $3536(52.20 \%)$ & 0.545 \\
\hline Male & $313(47.80 \%)$ & $688(49.70 \%)$ & $896(47.60 \%)$ & $1342(47.00 \%)$ & $3239(47.80 \%)$ & \\
\hline \multicolumn{7}{|l|}{ Season } \\
\hline Cold season & $288(43.97 \%)$ & $646(46.71 \%)$ & $993(52.71 \%)$ & $1894(66.39 \%)$ & $382 I(56.40 \%)$ & $<0.001$ \\
\hline Warm season & $367(56.03 \%)$ & $737(53.29 \%)$ & $891(47.29 \%)$ & $959(33.61 \%)$ & $2954(43.60 \%)$ & \\
\hline
\end{tabular}

patients were less than 66 years old or greater than 66 years old $(\mathrm{OR}=5.09,95 \%$ CI: $2.00-12.94 ; \mathrm{OR}=3.32,95 \%$ CI: $1.27-8.71)$.

\section{Discussion}

This study illustrates that greater numbers of CHD daily hospitalization strongly coincided with a reduction of air temperature in Tongliao, China. Additionally, the association

Table 2 The Summary of Descriptive Statistics During the Weather Conditions in 2017-2019

\begin{tabular}{|c|c|c|c|c|}
\hline & \multicolumn{3}{|c|}{$\begin{array}{l}\text { Daily Weather } \\
\text { Conditions }\end{array}$} & \multirow[t]{2}{*}{ Mean士SD } \\
\hline & $25 \%$ & $50 \%$ & $75 \%$ & \\
\hline \multicolumn{5}{|l|}{ Cold season (Oct-Mar) } \\
\hline Air temperature & -10.10 & -4.80 & 3.20 & $-3.46 \pm 8.4 I$ \\
\hline Air pressure & 996.3 & 1001.10 & 1005.4 & $100.87 \pm 6.73$ \\
\hline Wind velocity & 1.80 & 2.30 & 3.00 & $2.47 \pm 0.80$ \\
\hline Relative Humidity & 33.00 & 40.00 & 48.00 & $41.57 \pm 11.59$ \\
\hline Sunshine duration & 7.00 & 7.90 & 8.80 & $7.4 I \pm 2.89$ \\
\hline Water vapor pressure & 0.10 & 0.30 & 1.20 & $1.13 \pm 1.73$ \\
\hline \multicolumn{5}{|l|}{ Warm season (Apr-Sep) } \\
\hline Air temperature & 15.40 & 20.30 & 24.10 & $19.57 \pm 6.21$ \\
\hline Air pressure & 982.90 & 986.60 & 990.7 & $986.97 \pm 5.7 \mid$ \\
\hline Wind velocity & 2.00 & 2.50 & 3.00 & $2.70 \pm 0.93$ \\
\hline Relative Humidity & 32.00 & 53.00 & 70.00 & $51.91 \pm 21.24$ \\
\hline Sunshine duration & 6.90 & 8.40 & 11.30 & $8.39 \pm 3.96$ \\
\hline Water vapor pressure & 0.80 & 2.00 & 11.50 & $6.84 \pm 8.47$ \\
\hline \multicolumn{5}{|l|}{ All season } \\
\hline Air temperature & -5.00 & 9.20 & 20.10 & $7.87 \pm 13.69$ \\
\hline Air pressure & 986.20 & 993.70 & 1001.30 & $994.03 \pm 9.35$ \\
\hline Wind speed & 1.90 & 2.40 & 3.10 & $2.58 \pm 0.87$ \\
\hline Humidity & 32.50 & 43.00 & 58.00 & $46.66 \pm 17.79$ \\
\hline Sunshine hours & 6.90 & 7.92 & 9.80 & $7.89 \pm 3.33$ \\
\hline Water vapor pressure & 0.20 & 0.90 & 3.20 & $3.94 \pm 6.71$ \\
\hline
\end{tabular}

between low air temperature and acute CHD morbidity showed seasonal variation as, in the warm season, low air temperature was related to an increase in the number of CHD daily hospitalizations.

A relationship between weather factors and CHD has been reported in many countries, ${ }^{10,11}$ and with global warming, the impact of rising temperatures on health has caused widespread concern. Many studies have shown that there is a correlation between air temperature and CHD, especially under extreme temperature conditions, ${ }^{12-15}$ as the risk of CHD is significantly higher; however, Gasparrini has pointed out that the number of deaths caused by temperature far exceeds those due to extreme temperatures. ${ }^{15}$ Since 1938 , the impact of low air temperature on CHD has drawn attention around the world, ${ }^{16}$ and recent studies have also shown that low air temperature may be a risk factor for CHD. ${ }^{6,17}$ The results presented here are consistent with these observations. The underlying pathophysiological mechanism for this relationship is that low air temperature could cause an increase in blood pressure and blood viscosity, which in turn accounts for the low air temperature effects on CHD. ${ }^{18,19}$ However, we showed that low air temperature during the warm season may be associated with an increase in the number of CHD daily hospitalizations, and that this relationship does not hold true during the cold season. One possible explanation is that the study area is located in Northeast China. It is cold in winter and the elderly go out less frequently; Therefore, they are exposed to low air temperature for a shorter duration. Another reason is that outdoor activities are more frequent in the warm season than in the cold season. Importantly, the effect of air temperature on cardiovascular diseases has been described by U-shaped or V-shaped functions, implying that mortality is high both at very low and at very high temperatures. ${ }^{20-24}$ The annual average temperature of the study area is $0-6^{\circ} \mathrm{C}$, and 
Table 3 The Relationship Between Air Temperature and CHD Hospitalizations

\begin{tabular}{|c|c|c|c|c|c|c|}
\hline & \multicolumn{6}{|c|}{ CHD Daily Hospitalization Quartile } \\
\hline & \multicolumn{3}{|l|}{ Model I } & \multicolumn{3}{|l|}{ Model 2} \\
\hline & $\leq 66$ & $>67$ & ALL & $\leq 66$ & $>67$ & ALL \\
\hline \multicolumn{7}{|l|}{ Air temperature } \\
\hline I & $2.78(1.72,4.48)$ & $2.33(1.44,3.77)$ & $2.57(1.83,3.60)$ & $5.61(2.35,13.40)$ & $2.43(1.02,5.77)$ & $3.69(2.01,6.77)$ \\
\hline 2 & $3.62(2.22,5.92)$ & $2.58(1.60,4.15)$ & $3.01(2.14,4.23)$ & $5.86(2.79,12.32)$ & $2.71(1.32,5.58)$ & $3.86(2.31,6.44)$ \\
\hline 3 & $2.13(1.32,3.41)$ & $1.58(0.97,2.56)$ & $1.86(1.33,2.60)$ & $2.46(I .32,3.4 I)$ & $1.69(0.94,3.04)$ & $2.09(1.39,3.14)$ \\
\hline 4 & Reference & Reference & Reference & Reference & Reference & Reference \\
\hline
\end{tabular}

Notes: Model I: Unadjusted; Model 2: Adjusted for air pressure, wind velocity, relative humidity, sunshine duration, water vapor pressure.

Table 4 The Relationship Between Air Temperature and CHD Hospitalizations After Adjusting Other Meteorological Factor in Cold Season and Warm Season

\begin{tabular}{|c|c|c|c|c|c|c|}
\hline \multirow[t]{3}{*}{ Air Temperature } & \multicolumn{6}{|c|}{ CHD Daily Hospitalization Quartile } \\
\hline & \multicolumn{3}{|l|}{ Model I } & \multicolumn{3}{|l|}{ Model 2} \\
\hline & $\leq 66$ & $>67$ & ALL & $\leq 66$ & $>67$ & ALL \\
\hline \multicolumn{7}{|l|}{ Cold season } \\
\hline I & $0.79(0.40,1.60)$ & I.20 $(0.63,2.27)$ & $1.03(0.65,1.65)$ & I.II $(0.45,2.75)$ & I.0I $(0.46,2.25)$ & $1.03(0.57,1.87)$ \\
\hline 2 & $0.60(0.31,1.19)$ & I.2I $(0.63,2.33)$ & $0.92(0.58,1.47)$ & $0.73(0.33,1.59)$ & $\mathrm{I} .09(0.53,2.25)$ & $0.89(0.53,1.50)$ \\
\hline 3 & $0.74(0.37, \mathrm{I} .48)$ & I.42 $(0.74,2.73)$ & $1.09(0.68,1.73)$ & $0.83(0.40,1.73)$ & $\mathrm{I} .40(0.69,2.87)$ & $\mathrm{I} .08(0.65, \mathrm{I} .77)$ \\
\hline 4 & Reference & Reference & Reference & Reference & Reference & Reference \\
\hline \multicolumn{7}{|l|}{ Warm season } \\
\hline 1 & $3.68(1.81,7.46)$ & $2.47(I .24,4.9 I)$ & $3.02(1.85,4.94)$ & $5.09(2.00,12.94)$ & $3.32(I .27,8.7 I)$ & $4.48(2.32,8.68)$ \\
\hline 2 & $3.53(1.77,7.04)$ & $2.35(1.16,4.76)$ & $3.01(1.84,4.92)$ & $4.21(1.90,9.33)$ & $2.77(1.35,6.27)$ & $3.7 I(2 . I I, 6.5 I)$ \\
\hline 3 & $2.24(1.11,4.50)$ & I.9I $(0.96,3.81)$ & $2.07(1.27,3.37)$ & $2.61(1.28,5.33)$ & $2.05(1.04,4.20)$ & $2.4 \mathrm{I}(\mathrm{I} .46 .3 .98)$ \\
\hline 4 & Reference & Reference & Reference & Reference & Reference & Reference \\
\hline
\end{tabular}

Notes: Model I: Unadjusted; Model 2: Adjusted for air pressure, wind velocity, relative humidity, sunshine duration, water vapor pressure.

the results reported here correspond to the left part of the U-shaped or V-shaped distribution. However, one study has suggested that air temperature was not significantly correlated to myocardial infarction (MI) in winter, which in contrast to the results described here. This discrepancy can be explained as follows: (a) The current wide usage of climatic devices, such as air conditioners have altered the ambient temperature that people were accustomed to and (b) the ethnicity of the subjects, the climatic conditions of the area in which the study was conducted, and the environmental background potentially caused differences in the results.

We show that in the various age groups, lower air temperature was significantly associated with daily CHD hospitalizations. More than $70 \%$ of the patients in this study were older than 60 years, and almost all were elderly. Some studies have shown that CHD mortality in the elderly is linked to low air temperature ${ }^{25-27}$ as the ability to control the body temperature control decreases in the elderly with age, ${ }^{22,23}$ which makes the elderly more sensitive to cold temperatures. ${ }^{28,29}$ Additionally, several studies have suggested the presence of elevated fibrinogen levels among the elderly during winter, which is a marker of systemic inflammation. ${ }^{19,30,31}$ Schneider has observed that fibrinogen levels were associated with a decrease in air temperature among patients with MI. ${ }^{32}$ Another study showed enhanced FVII clotting activity values among the elderly. An increase in FVII could cause the blood to be in a hypercoagulable state. ${ }^{30}$ Once a coronary atherosclerotic plaque ruptures, a localized and strong clotting reaction is more likely to result in persistent, complete vascular occlusion. Therefore, FVII is closely associated with MI or fatal coronary events. ${ }^{33}$ However, the mechanisms that cause CHD are complex. In addition to external environmental factors, genetic factors and daily habits are also important players. ${ }^{34}$ Therefore, further studies are needed to validate these results. 


\section{Limitations}

First, this study did not consider the relationship between extreme air temperature and CHD daily hospitalizations. Second, we mainly considered the incidence of acute CHD; therefore, we did not perform hysteresis analysis. Third, patients in this study are not representative of the general Chinese population, and we could not make causal inferences.

\section{Conclusions}

Low air temperature might be a risk factor for CHD among the elderly, especially in the warm season. This study provides evidence that describe the effects of low air temperature on acute CHD morbidity and also provides suggestions for preventing acute CHD in the elderly. Furthermore, most of the temperature-related disease burden was attributable to cold temperatures. The effect of days of milder but non-optimum weather was substantially more than that attributable to extreme air temperature. Our results are important for planning public health interventions to minimize the health effects of adverse temperatures and predict the impact of climate change scenarios.

\section{Disclosure}

The authors report no conflicts of interest in this work.

\section{References}

1. Zhu KF, Wang YM, Zhu JZ, Zhou QY, Wang NF. National prevalence of coronary heart disease and its relationship with human development index: a systematic review. Eur J Prev Cardiol. 2016;23(5):530-543. doi:10.1177/2047487315587402

2. Ma YW L, Chen W. Introduction to the 2018 Chinese cardiovascular disease report. Chin J Hypertens. 2019;27(8):712-716.

3. De Smedt D, De Bacquer D, De Sutter J, et al. The gender gap in risk factor control: effects of age and education on the control of cardiovascular risk factors in male and female coronary patients. The EUROASPIRE IV study by the European Society of Cardiology. Int J Cardiol. 2016;209:284-290. doi:10.1016/j.ijcard.2016.02.015

4. Goerre S, Egli C, Gerber S, et al. Impact of weather and climate on the incidence of acute coronary syndromes. Int J Cardiol. 2007;118 (1):36-40. doi:10.1016/j.ijcard.2006.06.015

5. Panagiotakos DB, Chrysohoou C, Pitsavos C, et al. Climatological variations in daily hospital admissions for acute coronary syndromes. Int J Cardiol. 2004;94(2-3):229-233. doi:10.1016/j.ijcard.2003.04.050

6. Hampel R, Breitner S, Ruckerl R, et al. Air temperature and inflammatory and coagulation responses in men with coronary or pulmonary disease during the winter season. Occup Environ Med. 2010;67 (6):408-416. doi:10.1136/oem.2009.048660

7. Enquselassie F, Dobson AJ, Alexander HM, Steele PL. Seasons, temperature and coronary disease. Int J Epidemiol. 1993;22(4):632-636. doi:10.1093/ije/22.4.632

8. Liu L, Breitner S, Pan X, et al. Associations between air temperature and cardio-respiratory mortality in the urban area of Beijing, China: a time-series analysis. Environ Health. 2011;10:51. doi:10.1186/1476069X-10-51
9. Hajat S, Kovats RS, Lachowycz K. Heat-related and cold-related deaths in England and Wales: who is at risk? Occup Environ Med. 2007;64(2):93-100. doi:10.1136/oem.2006.029017

10. Barnett AG, Dobson AJ, McElduff P, et al. Cold periods and coronary events: an analysis of populations worldwide. J Epidemiol Community Health. 2005;59(7):551-557. doi:10.1136/jech.2004.028514

11. Wolf K, Schneider A, Breitner S, et al. Air temperature and the occurrence of myocardial infarction in Augsburg, Germany. Circulation. 2009;120(9):735-742. doi:10.1161/CIRCULATIONAHA.108.815860

12. Zanobetti A, O’Neill MS, Gronlund CJ, Schwartz JD. Susceptibility to mortality in weather extremes: effect modification by personal and small-area characteristics. Epidemiology. 2013;24(6):809-819. doi:10.1097/01.ede.0000434432.06765.91

13. Hajat S, O'Connor M, Kosatsky T. Health effects of hot weather: from awareness of risk factors to effective health protection. Lancet. 2010;375(9716):856-863. doi:10.1016/S0140-6736(09)61711-6

14. McMichael AJ, Wilkinson P, Kovats RS. International study of temperature, heat and urban mortality: the 'ISOTHURM' project. Int J Epidemiol. 2008;37(5):1121-1131. doi:10.1093/ije/dyn086

15. Baccini M, Kosatsky T, Analitis A. Impact of heat on mortality in 15 European cities: attributable deaths under different weather scenarios. $J$ Epidemiol Community Health. 2011;65(1):64-70. doi:10.1136/ jech.2008.085639

16. Bean WBMC. Coronary occlusion, heart failure and environmental temperatures. Am Heart J. 1938;16:701-713. doi:10.1016/S00028703(38)90952-4

17. Kunst AE, Looman CW, Mackenbach JP. Outdoor air temperature and mortality in The Netherlands: a time-series analysis. Am J Epidemiol. 1993;137(3):331-341. doi:10.1093/oxfordjournals.aje.a116680

18. Marchant B, Donaldson G, Mridha K, Scarborough M, Timmis AD Mechanisms of cold intolerance in patients with angina. $J$ Am Coll Cardiol. 1994;23(3):630-636. doi:10.1016/0735-1097(94)90747-1

19. Elwood PC, Beswick A, O'Brien JR, et al. Temperature and risk factors for ischaemic heart disease in the Caerphilly prospective study. Br Heart J. 1993;70(6):520-523. doi:10.1136/hrt.70.6.520

20. Weinbacher M, Martina B, Bart T, Drewe J, Gasser P, Gyr K. Blood pressure and atmospheric pressure. Ann $N$ Y Acad Sci. 1996;783:335-336. doi:10.1111/j.1749-6632.1996.tb26737.x

21. Liang WM, Liu WP, Chou SY, Kuo HW. Ambient temperature and emergency room admissions for acute coronary syndrome in Taiwan. Int $J$ Biometeorol. 2008;52(3):223-229. doi:10.1007/ s00484-007-0116-5

22. Sharovsky R, Cesar LA, Ramires JA. Temperature, air pollution, and mortality from myocardial infarction in Sao Paulo, Brazil. Braz $J$ Med Biol Res. 2004;37(11):1651-1657. doi:10.1590/s0100879x2004001100009

23. Baccini M, Biggeri A, Accetta G, et al. Heat effects on mortality in 15 European cities. Epidemiology. 2008;19(5):711-719. doi:10.1097/ EDE.0b013e318176bfcd

24. Nayha S. Cold and the risk of cardiovascular diseases. A review. Int J Circumpolar Health. 2002;61(4):373-380. doi:10.3402/ijch. v61i4.17495

25. Pan WH, Li LA, Tsai MJ. Temperature extremes and mortality from coronary heart disease and cerebral infarction in elderly Chinese. Lancet. 1995;345(8946):353-355. doi:10.1016/s01406736(95) $90341-0$

26. Marenberg ME, Risch N, Berkman LF, Floderus B, de Faire U. Genetic susceptibility to death from coronary heart disease in a study of twins. $N$ Engl J Med. 1994;330(15):1041-1046. doi:10.1056/NEJM199404143301503

27. Collins KJ. Low indoor temperatures and morbidity in the elderly. Age Ageing. 1986;15(4):212-220. doi:10.1093/ageing/15.4.212

28. Woodhouse PR, Khaw KT, Plummer M. Seasonal variation of blood pressure and its relationship to ambient temperature in an elderly population. $J$ Hypertens. 1993;11(11):1267-1274. doi:10.1097/ 00004872-199311000-00015 
29. Bokenes L, Alexandersen TE, Osterud B, Tveita T, Mercer JB. Physiological and haematological responses to cold exposure in the elderly. Int J Circumpolar Health. 2000;59(3-4):216-221.

30. Woodhouse PR, Khaw KT, Plummer M, Foley A, Meade TW. Seasonal variations of plasma fibrinogen and factor VII activity in the elderly: winter infections and death from cardiovascular disease. Lancet. 1994;343(8895):435-439. doi:10.1016/s0140-6736(94)92689-1

31. Kelly GS. Seasonal variations of selected cardiovascular risk factors. Altern Med Rev. 2005;10(4):307-320.

32. Schneider A, Panagiotakos D, Picciotto S, et al. Air temperature and inflammatory responses in myocardial infarction survivors. Epidemiology. 2008;19(3):391-400. doi:10.1097/EDE.0b013e31816 a4325
33. Puccetti L, Bruni F, Bova G, et al. Role of platelets in tissue factor expression by monocytes in normal and hypercholesterolemic subjects. In vitro effect of cerivastatin. Int J Clin Lab Res. 2000;30 (3):147-156. doi:10.1007/s005990070014

34. Derda AA, Woo CC, Wongsurawat T, et al. Gene expression profile analysis of aortic vascular smooth muscle cells reveals upregulation of cadherin genes in myocardial infarction patients. Physiol Genomics. 2018;50(8):648-657. doi:10.1152/physiolgenomics.00042.2017

\section{Publish your work in this journal}

Clinical Interventions in Aging is an international, peer-reviewed journal focusing on evidence-based reports on the value or lack thereof of treatments intended to prevent or delay the onset of maladaptive correlates of aging in human beings. This journal is indexed on PubMed Central, MedLine, CAS, Scopus and the Elsevier
Bibliographic databases. The manuscript management system is completely online and includes a very quick and fair peer-review system, which is all easy to use. Visit http://www.dovepress.com/ testimonials.php to read real quotes from published authors. 